\title{
Research on The Airplane Carbon Emissions and Low Carbon Solution in The Yangtze River Delta Airports
}

\author{
Lin Yan $^{1}$, Lin Miao ${ }^{2}$ \\ ${ }^{I}$ (Aeronautic Transportation College, Shanghai University of Engineering Science, China) \\ ${ }^{2}$ (Department of Mathematics, Minjiang University, China)
}

\begin{abstract}
: carbon emissions during airplane taking off and landing is a direct source of air pollution in the airport. For the low carbon development of civil aviation industry and environmental protection, based on the standard LTO cycle concept and engine emission data from the International Civil Aviation Organization, combined with the Chinese civil aviation airplane's data, this paper analyzes the annual airplane carbon emissions and carbon emission rate in 22 airports of Yangtze River Delta. The results show that the more number of airplane taking off and landing, the more carbon emissions of airplane in the airports, but for carbon emissions rate, the conclusion is different. Although small airplane has small fuel flow in the take-off and landing phase, it doesn't lead to a small carbon emission rate. On the basis of this result, combined with the actual situation of civil aviation industry in China, suggestion on low carbon solution to airport is developed.

Keywords: airplane, airport, carbon emissions, solution, Yangtze River Delta
\end{abstract}

\section{Introduction}

The development of economy promotes the prosperity of the air transport industry. During the period of 12th Five-Year, China sets up 70 new airports, rebuilds or expands 101 airports. Till 2015, there were 210 civil aviation airports in China (excluding Hong Kong, Macao and Taiwan). Although the airports meet the needs of people's lives, they bring huge air pollution problems. Air pollution in the airport is mainly from the emissions from the airplane taking off and landing, the discharge of the airport ground support equipment and the discharge of the airport vehicles. Among them, the emissions from the airplane taking off and landing is the main source of air pollution in the airport ${ }^{[1]}$.

Yangtze River Delta is the focus of China's economy development, where air transport industry is developing rapidly and the number of airports is intensive. In 2015, the number of airports in the Yangtze River Delta was 22. Therefore, taking Yangtze River Delta as example to calculate and analyze airplane carbon emissions in the airports is representative. China's domestic research focused on the European Union's ETS, the establishment of domestic carbon emission trading mechanism and new technology applications for low carbon $^{[2-5]}$. Quantitative calculation of airplane carbon emissions in the airports is seldom, so the research in the paper will benefit to the air transport industry energy conservation and emissions reduction, and provide the data support to the environment protection.

\section{Aircraft Take-Off And Landing Activities in The Airport}

In the airport, airplane take-off and landing activities can be described as the LTO cycle. The International Civil Aviation Organization (ICAO) defines the standard LTO cycle as the whole process of airplane take-off, climbing, landing and sliding in the airport with the altitude bellow $915 \mathrm{~m}$ (3000 feet). The duration of the 4 stage of the airplane activity has nothing to do with the engine thrust levels and type of airplane. Among them, the duration of take off is 0.7 minutes, climb is 2.2 minutes, approach-and-landing is 4 minutes, and sliding is 26 minutes $^{[6,7]}$. Thus, in a standard LTO cycle, the calculation formula of airplane carbon emissions is shown below:

$$
\mathrm{E}=\sum_{\mathrm{i}=1}^{4}\left(\mathrm{nt}_{\mathrm{i}} \mathrm{F}_{\mathrm{i}} \mathrm{I}_{\mathrm{i}}\right)
$$

where, $\mathrm{E}$ is $\mathrm{CO}_{2}$ emissions from airplane, $\mathrm{n}$ is the number of the airplane engine, $\mathrm{t}_{\mathrm{i}}$ is the airplane activity duration of every stage in a standard LTO cycle, $\mathrm{F}_{\mathrm{i}}$ is the single engine's fuel flow of every stage, $\mathrm{I}_{\mathrm{i}}$ is $\mathrm{CO}_{2}$ emission factor of fuel of every stage.

\subsection{Classification of Civil Airplane}

III. Airplane Carbon Emissions in The Yangtze River Delta Airports

There are many types of civil airplane in China. The mainstream types are the Boeing series and the Airbus series airplane. Referring to the classification standards of China's airport and the corresponding type of airplane that are allowed for takeoff and landing, the airplane can be divided into 5 categories, shown in table 1 . 
Table 1 Classification of civil airplane in China

\begin{tabular}{|l|l|l|}
\hline category & grade & type \\
\hline B & regional airplane & ERJ, ARJ, CRJ, etc. \\
\hline C & small trunk airplane & B737 series, A320 series \\
\hline D & medium trunk airplane & A330、A350、B767、B757、B787 \\
\hline E & large trunk airplane & A340、B777、B747 \\
\hline F & super trunk airplane & A380 \\
\hline
\end{tabular}

\subsection{Airplane Engine Fuel Flow}

The airplane engine fuel flow is determined by the airplane engine type, but airplane and engine type are not one-to-one correspondence, for example, A320 series airplane contains four types of airplane: A318, A 319, A320 and A321. Among them, taking A320 for instance, there are 5 kinds of optional engine types.

In the standard LTO cycle, the airplane engine fuel flow at various stages can be queried in engine emission data base of ICAO. Fuel flow of optional engine of A320 is shown in table 2.

Table 2 Fuel flow of optional engine of A320

\begin{tabular}{|l|l|l|l|l|l|}
\hline \multicolumn{2}{|l|}{ engine } & \multicolumn{4}{l|}{ fuel flow $(\mathrm{kg} / \mathrm{s})$} \\
\hline type & number & T/O & C/O & App & Idle \\
\hline V2500-A1 & 2 & 1.113 & 0.924 & 0.334 & 0.124 \\
\hline V2527-A5 & 2 & 1.053 & 0.880 & 0.319 & 0.128 \\
\hline CFM56-5A & 2 & 1.051 & 0.862 & 0.291 & 0.1011 \\
\hline CFM56-5A3 & 2 & 1.131 & 0.925 & 0.307 & 0.1044 \\
\hline CFM56-5B & 2 & 1.359 & 1.113 & 0.364 & 0.117 \\
\hline
\end{tabular}

Based on the airplane type that taking off and landing in the Yangtze River Delta airports, the corresponding engine type and fuel flow, the average value of fuel flow of each airplane category for the standard LTO cycle is calculated. The result is shown in table 3.

Table 3 Average value of fuel flow of each airplane category

\begin{tabular}{|l|l|l|l|l|}
\hline \multirow{2}{*}{$\begin{array}{l}\text { airplane } \\
\text { category }\end{array}$} & \multicolumn{4}{|l|}{ average value of fuel flow $(\mathrm{kg} / \mathrm{s})$} \\
\cline { 2 - 5 } & T/O & C/O & App & Idle \\
\hline B & 0.7882 & 0.6496 & 0.2198 & 0.0812 \\
\hline C & 1.1604 & 0.9509 & 0.3263 & 0.1122 \\
\hline D & 2.4361 & 1.9880 & 0.6684 & 0.2183 \\
\hline E & 2.5762 & 2.0913 & 0.6989 & 0.2302 \\
\hline F & 2.6423 & 2.1997 & 0.7203 & 0.2680 \\
\hline
\end{tabular}

At present, the engine number of B, C, D airplane is 2, in the E class, the engine number of B777 is 2, while the engine number of A340 or B747 is 4, and the engine number of F class airplane is also 4, so they should be calculated separately.

In the standard LTO cycle, at sea level altitude and temperature $15^{\circ} \mathrm{C}$, the $\mathrm{CO}_{2}$ emission factor of each phase of the flight is 3.115. Therefore, based on above analysis and the formula (1), carbon emissions of each airplane category in a standard LTO cycle are calculated. The result is shown below:

$\mathrm{E}_{\mathrm{B}}=\sum_{\mathrm{i}=1}^{4}\left(\mathrm{nt}_{\mathrm{i}} \mathrm{F}_{\mathrm{i}} \mathrm{I}_{\mathrm{i}}\right)$

$=2 \times 3.115 \times 60 \times(0.7 \times 0.7882+2.2 \times 0.6496+4 \times 0.2198+26 \times 0.0812)=1858.3 \mathrm{~kg}$

in a similar way, $\mathrm{E}_{\mathrm{C}}=2663.9 \mathrm{~kg}, \mathrm{E}_{\mathrm{D}}=5393.3 \mathrm{~kg}$;

for the 2 engine case, $E_{\mathrm{E}}=5676.2 \mathrm{~kg}$, for the 4 engine case, $\mathrm{E}_{\mathrm{E}}=11352.4 \mathrm{~kg}$;

$\mathrm{E}_{\mathrm{F}}=12363.9 \mathrm{~kg}$

\subsection{Airplane LTO Cycle Number}

In theory, airplane LTO cycle number should be calculated during one year. However, the airlines only release two versions of flight schedule in a year: winter-spring flight schedule and summer-autumn flight schedule. Despite temporary flights and abnormal flights, civil flight follows these two schedules, repeating every week. This paper collects the taking off and landing data of the Yangtze River Delta airports, one week data from winter-spring flight schedule and another week data from summer-autumn flight schedule, then calculates the proportion of taking off and landing of each airplane class, named $\mathrm{N}_{\mathrm{i}}$, combining with the total taking off and landing number during one year in the Yangtze River Delta airports, named M, finally the annual LTO cycle number for each airplane category can be calculated by $\mathrm{N}_{\mathrm{i}} \times \mathrm{M}$. The proportion of taking off and landing of each airplane category and the total taking off and landing number in the Yangtze River Delta airports are shown in table 4. 
Table 4 Proportion and total number of airplane taking off and landing in the Yangtze River Delta airports in 2015

\begin{tabular}{|c|c|c|c|c|c|c|c|}
\hline \multirow[t]{3}{*}{ airport } & \multicolumn{6}{|c|}{ proportion of airplane taking off and landing $\mathrm{Ni}(\%)$} & \multirow{3}{*}{$\begin{array}{l}\text { total taking } \\
\text { off and } \\
\text { landing } \\
\text { number in } \\
2015\end{array}$} \\
\hline & \multirow{2}{*}{$\begin{array}{l}\text { B } \\
\text { 2engines }\end{array}$} & \multirow{2}{*}{$\begin{array}{l}\mathrm{C} \\
\text { 2engines }\end{array}$} & \multirow{2}{*}{$\begin{array}{l}\text { D } \\
\text { 2engines }\end{array}$} & \multicolumn{2}{|l|}{$\mathrm{E}$} & \multirow{2}{*}{$\begin{array}{l}\text { F } \\
\text { 4engines }\end{array}$} & \\
\hline & & & & 2engines & 4engines & & \\
\hline Shanghai Pudong & 0 & 74.42 & 16.16 & 5.8 & 2.9 & 0.71 & 449,171 \\
\hline Shanghai Hongqiao & 0 & 81.85 & 14.58 & 2.856 & 0.714 & 0 & 256,603 \\
\hline Hangzhou Xiaoshan & 3.42 & 93.75 & 2.56 & 0.149 & 0.111 & 0 & 232,079 \\
\hline Nanjing Lukou & 0.91 & 96.03 & 2.51 & 0.28 & 0.28 & 0 & 166,858 \\
\hline Wenzhou Longwan & 2.33 & 96.44 & 1.23 & 0 & 0 & 0 & 61,750 \\
\hline Hefei Xinqiao & 9.68 & 90.16 & 0.17 & 0 & 0 & 0 & 57,294 \\
\hline Ningbo Lishe & 2.89 & 96.34 & 0.78 & 0 & 0 & 0 & 56,110 \\
\hline Wuxi Shuofang & 0.58 & 96.32 & 3.1 & 0 & 0 & 0 & 38,569 \\
\hline Xuzhou GuanYin & 13.1 & 86.9 & 0 & 0 & 0 & 0 & 31,789 \\
\hline Yangzhou Taizhou & 9.27 & 90.73 & 0 & 0 & 0 & 0 & 30,614 \\
\hline Changzhou Benniu & 4 & 96 & 0 & 0 & 0 & 0 & 26,347 \\
\hline Nantong Xingdong & 0 & 100 & 0 & 0 & 0 & 0 & 22,537 \\
\hline Zhoushan Mount Putuo & 6.29 & 93.7 & 0 & 0 & 0 & 0 & 20,527 \\
\hline Yiwu & 17.21 & 82.79 & 0 & 0 & 0 & 0 & 11,272 \\
\hline Huaian Lianshui & 0 & 100 & 0 & 0 & 0 & 0 & 10,048 \\
\hline Yencheng Nanyang & 0 & 100 & 0 & 0 & 0 & 0 & 8,842 \\
\hline Lianyungang Baitabi & 7.84 & 92.16 & 0 & 0 & 0 & 0 & 7,802 \\
\hline HuangshanTunxi & 25.56 & 74.44 & 0 & 0 & 0 & 0 & 6,454 \\
\hline Fuyang & 44.44 & 55.56 & 0 & 0 & 0 & 0 & 5,908 \\
\hline Taizhou Luqiao & 22.63 & 77.37 & 0 & 0 & 0 & 0 & 4,708 \\
\hline Chizhou Jiuhuashan & 0 & 100 & 0 & 0 & 0 & 0 & 3,290 \\
\hline Quzhou & 0 & 100 & 0 & 0 & 0 & 0 & 1,792 \\
\hline
\end{tabular}

\subsection{Annual Carbon Emissions of Airplane in the Airport}

Based on above analysis, the annual carbon emissions of the airplane in the airport can be written as that: $\mathrm{Q}=\left(\mathrm{E}_{\mathrm{B}} \times \mathrm{N}_{\mathrm{B}}+\mathrm{E}_{\mathrm{C}} \times \mathrm{N}_{\mathrm{C}}+\mathrm{E}_{\mathrm{D}} \times \mathrm{N}_{\mathrm{D}}+\mathrm{E}_{\mathrm{E}} \times \mathrm{N}_{\mathrm{E}}+\mathrm{E}_{\mathrm{F}} \times \mathrm{N}_{\mathrm{F}}\right) \times \mathrm{M} / 2$

where, $N_{B}$ is the proportion of take-off and landing of class $B$ airplane in a year, similarly, $N_{C}, N_{D}, N_{E}, N_{F}$ is for class C, D, E, F airplane.

According to the formula (2), we can calculate the carbon emissions of airplane in the Yangtze River delta airports in 2015. Currently, carrying passenger is main tasks of domestic flights in China, carbon emissions rate is calculated from dividing annual carbon emissions of airplane in the airport by the annual passenger throughput, as shown in Table 5. It is clear that the carbon emissions rate is more meaningful from the environmental protection and social efficiency point of view.

From the calculation results, the conclusion is that the more number of airplane taking off and landing, the more carbon emissions of airplane in the airports, but for carbon emissions rate, the conclusion is different. Although small airplane has small fuel flow in the take-off and landing phase, it doesn't lead to a small carbon emission rate. For example, Fuyang airport, the taking off and landing number and carbon emissions are low, ranking No.19, the proportion of class B airplane is No.1, but the carbon emission rate is No.8. Shanghai Hongqiao airport is No.2 for the taking off and landing number and carbon emissions, while the carbon emission rate is No.21 without class B airplane. Therefore, to reduce air pollution in the airports, simply promoting the use of small airplane or big airplane is not a good choice. The solution is to optimize the structure of airplane fleet and route, then raise the passenger load rate, according to the passenger flow.

Table 5 Carbon emissions of airplane in the Yangtze River Delta airports in 2015

\begin{tabular}{|l|l|l|l|}
\hline airport & carbon emissions $(\mathrm{t})$ & carbon emissions rate $(\%)$ & carbon emissions rate ranking \\
\hline Shanghai Pudong & 808565 & 1.35 & 11 \\
\hline Shanghai Hongqiao & 411837 & 1.05 & 21 \\
\hline Hangzhou Xiaoshan & 315638 & 1.11 & 19 \\
\hline Nanjing Lukou & 1.20 & 13 \\
\hline Wenzhou Longwan & 82705 & 1.12 & 17 \\
\hline Hefei Xinqiao & 74219 & 1.08 & 20 \\
\hline Ningbo Lishe & 1.13 & 16 \\
\hline Wuxi Shuofang & 14687 & 3.15 & 15 \\
\hline Xuzhou GuanYin & 4.59 & 3 \\
\hline Yangzhou Taizhou & 40664 & 1.91 & 1 \\
\hline Changzhou Benniu & 39633 & 2.58 & 6 \\
\hline Nantong Xingdong & 34668 & 4.16 & 5 \\
\hline Zhoushan Mount Putuo & 30018 & 1.19 & 2 \\
\hline Yiwu & 26818 & 14 \\
\hline
\end{tabular}


Research on The Airplane Carbon Emissions and Low Carbon Solution in The Yangtze River Delta...

\begin{tabular}{|l|l|l|l|}
\hline Huaian Lianshui & 13383 & 2.65 & 4 \\
\hline Yencheng Nanyang & 11777 & 1.38 & 10 \\
\hline Lianyungang Baitabi & 10145 & 1.43 & 9 \\
\hline HuangshanTunxi & 7932 & 1.34 & 12 \\
\hline Fuyang Xiguan & 6812 & 1.55 & 8 \\
\hline Taizhou Luqiao & 5842 & 1.00 & 22 \\
\hline Chizhou Jiuhuashan & 4382 & 1.61 & 7 \\
\hline Quzhou & 1.12 & 18 \\
\hline
\end{tabular}

\section{Low Carbon Solution in Yangtze River Delta Airports}

To solve the carbon emissions problem, cooperation between the airport, airline and air traffic management bureau is needed. Based on the actual situation of civil aviation industry in China, combined with the above analysis, this paper puts forward the following countermeasures.

\subsection{Upgrade Airplane Fleet and Optimize the Airplane Configuration of Route}

Usually, airplane's performance is increased by $50 \%$ by new generation of airplane and engine. In order to reduce energy consumption, the airlines can introduce more advanced airplane if the cost is acceptable. It can not only enhance the performance of the flight fleet, but also further reduce carbon emissions. Meanwhile, the airline should configure the airplane type for each route based on the actual passenger number. For example, replace the original narrow body trunk airplane by regional airplane for the route with fewer passengers. And in high traffic routes, using more advanced big aircrafts instead of small and medium-sized aircrafts. That can allocate aviation resources reasonably and effectively, and greatly reduce fuel consumption.

\subsection{Reduce the Using of APU on the Ground}

APU is the abbreviation for airplane auxiliary power unit. It is a small gas turbine engine. Its role is to provide independent power and compressed air to the airplane. During the period of takeoff, the APU can improve take-off performance. On the ground, APU can ensure the cabin lighting and air conditioning working correctly. However, its efficiency is low, so the fuel consumption is relatively large. The fuel consumption for the operation of the APU is about $70 \sim 400 \mathrm{~kg} / \mathrm{h}$. According to IATA data, the cost of running APU is usually 5 times of the cost of the running ground equipment. Therefore, the airport should widely use the boarding bridge equipment to replace the APU on the ground, which can save a lot of fuel costs and maintenance costs of the APU, greatly reduce the air pollution.

\subsection{Shorten Sliding Time of Airplane}

In the standard LTO cycle, the airplane ground sliding time is up to 26 minutes, and fuel consumption is about $40 \%$ of the entire LTO cycle stage. Therefore, the airport should be reasonable to plan airport layout, improve the sliding route, and shorten the airplane sliding time to reduce the amount of carbon emissions.

\subsection{Enhance the Control Capability of Air Traffic Management Bureau}

Air traffic management bureau should establish a reasonable airspace usage rule, improve the control capability, build orderly and convenient air traffic environment and reduce unnecessary hovering in the air and waiting time on the ground.

\subsection{Usage of Bio Fuels}

It is an effective way to reduce the carbon emissions by using of bio fuels instead of fuel. Mature biological fuel supply system is not built yet in China, and research, development and production of bio fuels need a lot of money. Therefore, government should publish encourage policies to build a good environment for the development of bio fuels. Meanwhile, the China aviation transportation enterprises should actively participate in the development and usage of bio fuels. Only in this way can we finally realize the zero emission of flight.

\section{Conclusion}

With the development of air transportation industry, the carbon emissions problem of airplane in the airport can't be ignored. The analysis of this paper is based on the standard LTO cycle, which is an ideal simulation of the actual situation. Duration of the actual airplane taking off and landing is not the same as the duration of standard LTO cycle. Meanwhile, from the official website of ICAO, the fuel flow is measured by airplane manufacturers in the international standard atmosphere environment, which is also different from the value in the actual operation state. Therefore, the study on airplane carbon emissions of standard LTO cycle in the Yangtze River Delta airports is the first step work to reduce the environmental pollution of the airport. It needs further study in accordance with the actual flight of the airplane. 


\section{References}

[1] Ding Wenshan, Cai Liangcai, Shao Bin, Ding Fei. research on airport air pollution status. Journal of Environmental Engineering, (6), 2014, 69-72.

[2] Gong hui. Influence of the low carbon storm on the air transport industry and the countermeasures. Comprehensive transportation, (1), 2010, 55-58.

[3] Ma jun. The countermeasure analysis of China's air transport industry to carry out the policy of low carbon transportation. Foreign economic and trade, (10), 2010, 79-81.

[4] Zhang hui, Wang zhengyuan. Discussion on the development strategy of air transport industry in the era of low carbon economy. Air transport business, (2), 2011, 41-43.

[5] Cai yufeng. Under the new situation to our country airline company energy conservation and emission reduction work ponder, Air transport business, (16), 2009, 4-7.

[6] Lu Zhi, Liu Yonghong, Xu Weijia, Chen Ziyang. Study on the calculation of the carbon emission and low carbon strategy based on ICAO, Journal of Re-source Saving and Environmental Protection, (9), 2014, 129-130.

[7] Luo Xiaogang. Study on the carbon emission of China's aviation industry based on life cycle theory: a case study of the Yangtze River Delta region. Nanjing University of Aeronautics \& Astronautics, 2013

[8] Xia Qing, Zuo Hongfu, Yang Junli. China civil aviation aircraft off landing (LTO) cycle emissions estimation, Journal of Environmental Sciences, (7), 2008, 1469-1474.

[9] Chen Xiao. Airlines should vigorously reduce the aircraft APU ground using the [J/OL]. civil aviation resource net, $2010-02-01$.

[10] China Civil Aviation Administration of planning and development of the financial secretary. From the statistical view of the civil aviation 2015, Beijing: China Civil Aviation press, 2016 